\title{
Vaginal Cancer cM1 TNM Finding v8
}

National Cancer Institute

\section{Source}

National Cancer Institute. Vaginal Cancer cM1 TNM Finding v8. NCI Thesaurus. Code C139636.

Vaginal cancer with distant metastasis. (from AJCC 8th Ed.) 